
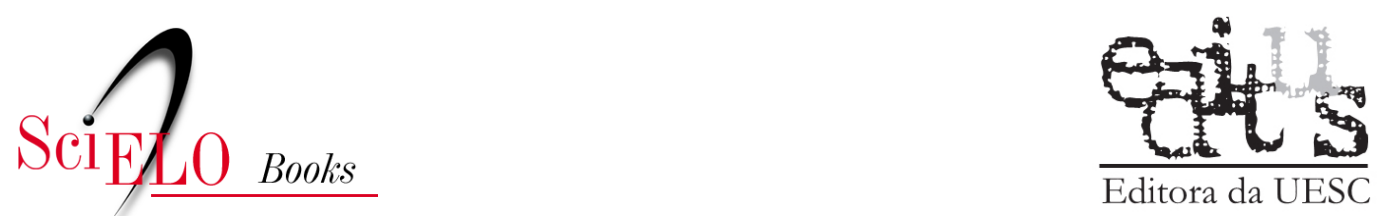

\title{
Imagens de si, imagens do outro construção de identidades e alteridade entre idosas
}

\author{
Benedita Edina da Silva Lima Cabral \\ Kátia Ramos Silva
}

\section{SciELO Books / SciELO Livros / SciELO Libros}

CABRAL, B. E. S. L., and SILVA, K. R. Imagens de si, imagens do outro: construção de identidades e alteridade entre idosas. In: D'ALENCAR, R. S., ed. $A$ representação social na construção da velhice [online]. Ilhéus, BA: EDITUS. 2017, pp. 61-87. ISBN: 978-85-7455-486-0. https://doi.org/10.7476/9788574554860.0004.

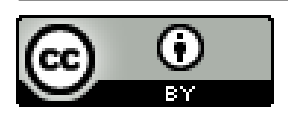

All the contents of this work, except where otherwise noted, is licensed under a Creative Commons Attribution 4.0 International license.

Todo o conteúdo deste trabalho, exceto quando houver ressalva, é publicado sob a licença Creative Commons Atribição 4.0.

Todo el contenido de esta obra, excepto donde se indique lo contrario, está bajo licencia de la licencia Creative Commons Reconocimento 4.0. 


\title{
IMAGENS DE SI, IMAGENS DO OUTRO: CONSTRUÇÃO DE IDENTIDADES E ALTERIDADE ENTRE IDOSAS ${ }^{1}$
}

\author{
Benedita Edina da Silva Lima Cabral ${ }^{2}$ \\ Kátia Ramos Silva ${ }^{3}$
}

\section{Introdução}

\begin{abstract}
A representação de si é como um jogo de espelhos que reflete, através da representação do outro, a imagem que cada um tem de si (PEIXOTO, 1997, p. 156).
\end{abstract}

- Eu não sei porque é velho, num acho nada. (...) Eu sou velha e não quero ser, mas com a vida dos outros, eu não sei. (...) Cada um tem o seu jeito de envelhecer. Eu não sei dos outros, só sei do meu. Minha velhice é sem querer ser velha, já tenho noventa e quatro anos (Sra I., 94 anos, ILPI).

O processo de envelhecer é alvo de múltiplas análises e percepções, uma vez que o crescente índice de pessoas

1 Este trabalho é uma versão do terceiro capítulo da dissertação de mestrado apresentada em fevereiro de 2012, no Programa de Pós-Graduação em Sociologia - UFPB.

2 Doutora em Ciências Sociais - UNICAMP. E-mail: <beneditaedina@ yahoo.com.br>

3 Doutoranda em Sociologia - PPGS/UFPB. E-mail: <katya6@gmail.com> 
idosas evidencia demandas. A indústria estética, turística, de entretenimento e de publicidade para atender e/ou criar necessidades nos indivíduos pertencentes à "terceira idade", a mídia e seus métodos de promoção da longevidade com "qualidade de vida", as contraditórias decisões do setor público para lidar com o aumento da expectativa de vida colocam a velhice como uma categoria complexa e homogênea, dotada de significados e necessidades semelhantes. Diferentemente, este estudo realiza uma análise sobre as "velhices" observadas nas relações estabelecidas entre indivíduos idosos oriundos de contextos sociais e com trajetórias de vida distintas.

Assim, o objetivo é confrontar e analisar as diferenças presentes no processo de envelhecer, para conhecer como são produzidos os significados sociais sobre a velhice, na perspectiva da alteridade, através do trabalho das idosas voluntárias da Associação Internacional de Caridades (AIC), "Senhoras da Caridade", e dos idosos residentes no Instituto São Vicente de Paulo, Instituição de Longa Permanência para Idosos (ILPI), em Campina Grande, PB, dirigido por religiosas.

A AIC é uma organização leiga, composta, em sua maioria, por idosas de classe média, que atua em segmentos socialmente excluídos, dentre eles, os idosos institucionalizados. Pretendemos discutir sobre a construção de identidade e o reconhecimento de si, entre voluntárias da AIC, em face da imagem do outro, os residentes, com quem compartilham o estágio etário, mas apresentam estilos de vida distintos.

A proposta é compreender como se dá o encontro e/ ou embate entre velhices, identificar as fronteiras e aproximações entre a chamada velhice ativa/saudável e a velhice institucionalizada/doente/pobre para perceber como os membros de cada grupo social reconhecem-se no outro, identificando suas necessidades e características socioculturais e subjetivas. 
A AIC possui um histórico internacional e foi fundada no Brasil em 1854. O núcleo de Campina Grande, PB, foi instituído no ano de 1935 e funciona nas dependências do Instituto São Vicente de Paulo. Este núcleo, denominado Associação das Voluntárias da Caridade São Vicente de Paulo, é composto por 76 mulheres, algumas com formação acadêmica e vida social ativa e reconhecidas no contexto da prática da caridade. Dentre os projetos que a AIC desenvolve, destacamos o "Projeto Alegrar", especificamente voltado para os idosos residentes.

A proposta está pautada na perspectiva do confronto entre o eu e o outro na velhice. Inicialmente ponderamos sobre os aspectos motivadores para permanecerem no grupo de caridade e, por outro lado, como residentes de uma instituição de longa permanência. Em seguida, discutimos a construção de identidade e a perspectiva da alteridade entre as voluntárias e os residentes. E, através da observação de práticas cotidianas e dos diálogos estabelecidos com os informantes, elaboramos o percurso sobre percepções mútuas de ser idoso.

As atividades desenvolvidas no "Projeto Alegrar", junto aos residentes, permitiram que elas conheçam outras faces da velhice - doentia, solitária, excluída, invisível - e, ao mesmo tempo, vislumbrem formas diferentes de vivenciar essa fase da vida. Parte das mulheres que compõem a AIC apresentam características opostas à velhice institucional. Por exemplo, algumas frequentam academias estéticas, bailes e passeios turísticos, sugerindo que, na velhice, podem ser saudáveis, ativas e engajadas em causas sociais (DEBERT, 1999). Assim, o status social evidenciado e a vinculação a um grupo da caridade, reconhecido como parte de uma elite, contribuem para que a dúplice imagem da velhice: que ora é apresentada como doentia e decrépita, ora como saudável e ativa, seja reconhecida no cotidiano. Como analisado por Debert: 
Quando a referência do pesquisador no tratamento de categorias como velhos, jovens, adolescentes e crianças é o número de anos vividos a partir da data de nascimento ou a aparência de cada um, acaba-se por perder a plasticidade das formas pelas quais o curso da vida é concebido em sociedades distintas, bem como o sentimento investido na relação entre grupos etários e a importância desses grupos e categorias na organização social $(2007$, p. 55).

Parece ser na velhice, mais do que em outras etapas da vida, que díspares papéis e oportunidades sociais são evidenciados. Além das variações de ordem subjetiva, as distinções de gênero, geração e classe social, influenciam as vivências de ser velho conforme documentado em diversas pesquisas. Aqui, discutimos as ambiguidades do processo de envelhecer, expressas nas práticas desenvolvidas pelas "Senhoras da Caridade" junto aos idosos institucionalizados.

Analisamos como as "Senhoras da Caridade" encontram-se com uma imagem repelida socialmente, o outro feio, rejeitado, doente, a concretude de uma velhice temida. Esse outro também depara-se com uma forma de viver, que jamais terá acesso, não reconhecendo-se nessas "Senhoras" vestidas de acordo com a moda, preocupadas com a aparência e que demonstram vitalidade. A relação estabelecida entre idosos de contextos e grupos tão diferenciados reflete questões na própria construção de identidade e da alteridade em face da imagem do outro que, embora compartilhe o estágio etário comum, vivencia e reconhece a velhice diferentemente.

\section{Inserção e permanência dos idosos nos espaços da ILPI e na AIC}

Possuidores de experiências peculiares, acumuladas ao longo dos anos, os entrevistados relatam histórias de 
vida e retomam vivências do passado, aspectos vividos no presente e as perspectivas de futuro em seus espaços de sociabilidade.

Sabemos que o cotidiano e as reflexões sobre o tempo atual e expectativa dos idosos são intrinsecamente relacionados ao grupo social onde estão inseridos. Peixoto (1997, p. 152) mostrou como mulheres idosas refletem suas experiências ao narrarem "histórias de vida, em geral, carregadas de emoção, que melhor ressaltam os conteúdos sociais da memória familiar, permitindo descobrir as normas e valores transmitidos, os lugares de vida e as relações familiares".

A possibilidade de nos debruçar sobre velhices particularizadas, nesse exercício de percorrer por entre as linhas da vida dos idosos durante a pesquisa, adquire uma dimensão ainda mais significativa para a construção de um panorama sobre as diferenças no processo de envelhecer.

Assim, entender o que é residir numa instituição ou participar de uma reconhecida associação de caridade constitui um campo de observação de processos relacionais entre idosas tão diversas. Múltiplos aspectos que condicionaram os idosos a buscar inserção em tais ambientes distintos, implica buscar conhecer as variadas motivações para permanecer neles. Nessa análise, temos uma tentativa de explicitar aspectos constitutivos das narrativas dos entrevistados, articulados às observações diretas e conversas informais estabelecidas no ambiente da pesquisa.

\section{Idosas residentes}

"O que levou determinado idoso a procurar abrigo na instituição?”. Necessidades financeiras, abandono, solidão, ausência de suporte. Essas são as respostas comuns a tal questão. Segundo a religiosa diretora da ILPI, a entrada dos idosos obedece aos seguintes procedimentos: primeiro, deve ser enviada uma solicitação ao Instituto requerendo 
o ingresso do idoso; segundo, membros da instituição realizam visita ao domicílio onde se encontra e, após confirmarem a idade, a falta de recursos e de apoio da família, é, então, firmado um contrato de prestação de serviços, constando os direitos e deveres atribuídos à instituição e ao idoso, ou seu representante legal, no caso dos indivíduos que não apresentam autonomia física e/ou mental.

Não houve aproximação com os homens residentes, visto que havia pouca frequência deles nos momentos promovidos pelas caridosas. Assim, nosso foco foram as relações entre voluntárias e idosas residentes. Entrevistamos apenas um homem idoso e quatro idosas contribuíram para a pesquisa. A faixa etária variou entre 63 e 94 anos, conforme os critérios utilizados para compor a pesquisa. Todos os entrevistados são naturais de municipios próximos da cidade, possuem apenas o ensino básico e não conquistaram estabilidade profissional. As mulheres trabalharam como "empregadas domésticas" ou no "próprio lar" e algumas foram costureiras. Uma trabalhou como cuidadora de criança doente e como auxiliar de enfermagem. O homem entrevistado trabalhou como tipógrafo.

Entre os cinco entrevistados, duas são solteiras, uma viúva, um divorciado e uma idosa que nunca casou legalmente, mas teve dois filhos de um relacionamento. Exceto as solteiras, todos têm filhos, netos e, em alguns casos, até bisnetos. Antes da inserção na instituição, residiam com familiares, sobrinhos, filhos e/ou genros/noras. O idoso entrevistado é peculiar, visto que residia com a mãe e, após a morte dela, uma tia encaminhou-o para a instituição, por não poder ser sua cuidadora. Todas as mulheres residem na instituição há cerca de 1 (um) ano e o homem há mais de cinco anos.

O perfil revela aspectos das vivências das residentes. As idosas que não constituíram família e são solteiras atribuem essa condição às restrições impostas pelos familiares, que impediram relações afetivas durante a juventude. 
Outras demonstram orgulho em serem "moças solteiras". O relato de uma idosa ilustra esse "orgulho" de preservar a castidade, mesmo após a morte dos pais e a consequente solidão que marcou sua vida. Ao narrar acontecimentos biográficos, ela afirma:

- ... vou levando a vida, nunca casei, sou solteira, nunca fiz besteira também. Sempre tive muito cuidado na minha vida; fazer coisa errada, nunca fiz, graças a Deus, e tenho boas amizades (Sra. M., 89 anos, ILPI).

As viúvas apontam esse fato como o motivo de sua entrada no local, visto que estão "sozinhas no mundo". As que têm família numerosa, filhos, netos e rede familiar na cidade ou municípios circunvizinhos apontam outros aspectos para residir na instituição. Vida profissional intensa e consequente falta de tempo dos familiares para cuidar de seus idosos, difícil convivência com genros/noras, conflitos intergeracionais com os netos são os principais motivos apresentados para justificar distanciar-se da convivência familiar, optando ou sendo impelido a procurar uma ILPI. Encontramos também idosos que tomaram a iniciativa em lá residir.

Residente há um ano, uma idosa explica que morava com uma filha, mas devido à intensa vida profissional desta, não dispunha de tempo para ser sua cuidadora:

- É porque sou doente, doente e essa filha ela é muito... . Não podia pagar porque ela já é empregada, ganha um salário e é doente. O jeito que teve, ela arrumou aqui, que é mesmo morar mais ela (Sra. I., 94 anos, ILPI).

Revelou ter outros três filhos que a visitam regularmente. Justifica que todos são muito “ocupados" e não poderiam cuidar dela. Em seu depoimento, é recorrente afirmar os beneficios de morar na ILPI e elogiar religiosas e funcionárias, numa atitude de "defesa" da instituição, 
chegando a dizer que ainda que a filha lhe oferecesse novamente moradia, não deixaria o espaço institucional.

Outra idosa de 90 anos, viúva, com doze filhos que residem no estado do Rio de Janeiro, demonstrou satisfação em morar na instituição. O relato é esclarecedor:

- Eu morava mais o filho caçula, sabe? Mas a nora era ruim, eu chorava todo dia pra vim pra cá. Quando cheguei aqui que a freira me viu, eu chorei, ai ela disse: 'Olhe, não chore não que você vai ficar. Tem cama, tem guarda-roupa, não falta nada, só basta trazer os troços. Só os vestidinhos, as coisinhas, né?' Tô amando, tô no céu. É uma maravilha (Sra. R., 90 anos, ILPI).

Nesses fragmentos, percebemos que a instituição adquire significado para muitos deles. Embora a ILPI atue como uma "fuga" da solidão/rejeição e violência familiar, eles reconhecem nesse espaço uma oportunidade para serem cuidados, conquistarem a desejada tranquilidade, além de "recriar laços" (CABRAL, 2002) com os demais residentes e os cuidadores da instituição. Born e Boechat afirmam que "se o indivíduo vem de precária situação social, a ILP será o porto seguro, de acolhedora segurança e tranquilidade" (2002, p. 773).

Ainda que revelem tristeza e certa angústia com a omissão dos filhos diante da violência e do abandono, esclarecem os aspectos positivos do seu novo lugar de vivência, visto que, como observamos acima, “...o fato de os idosos viverem com os filhos não é garantia da presença do respeito e prestígio nem da ausência de maus-tratos" (DEBERT, 1999, p. 83). Contudo, devemos considerar que essa recorrente ênfase percebida nos discursos de alguns pode revelar um recurso de resistência à situação de fragilidade social em que se encontram e, para tanto, supervalorizam a ILPI e sua inserção no local.

A observação e análise dos discursos nos permite entrever que, além da ausência dos familiares e fatores 
biológicos, outros elementos influenciam essa deterioração mental e emocional dos idosos. Um é a desvinculação da própria casa, atividades domésticas ou profissionais, visto que o ambiente atual não remete a vivências anteriores a essa experiência. Além disso, o afastamento de sua rede de sociabilidade (CABRAL, 2002) e a ausência de atividades diárias que estimulem o corpo e a mente surgem como possiveis motivos do agravamento de doenças. Destacamos uma idosa de 90 anos que, embora os familiares não a visitem regularmente, afirma satisfação com a residência no local, pois ainda trabalha confeccionando bonecas e tapetes com retalhos de tecidos doados. Ela aproveita a presença de visitantes e comercializa os artesanatos que produz.

É relevante considerar atitudes que explicitam a tentativa de preservar a individualidade nesse ambiente, a nova "casa". Atitudes como pedir para serem chamadas pelo nome próprio e não pela expressão "senhora", mostrar fotografias de vida "pré-institucional", apresentar os visitantes aos demais residentes, afirmando que se trata de seu "amigo/a" ou familiar, revelam estratégias de resistência adotadas para atenuar a sensação de estranhamento ao ambiente institucional. A tentativa de preservar a intimidade no coletivo, demarcando o espaço individual no dormitório feminino acontece através de objetos, fotografias e outros elementos de distinção.

Ao tornar-se residente na ILPI, o idoso é condicionado a desvincular-se dos antigos papéis que exercia e adaptarse a novos papéis sociais, não sem vivenciar inúmeras dificuldades emocionais e comportamentais nesse processo de mudanças intensas. As amizades, o companheirismo e a solidariedade observada entre os residentes configuram um importante meio de adaptação dos idosos.

Para se manterem lúcidas, atualizadas e ativas, elas procuram desenvolver atividades manuais, escutar o rádio para ouvir as notícias e ver televisão, atividade muito 
apreciada. A possibilidade de gerir uma pequena parte de sua aposentadoria atua como relevante fator para a autoestima daqueles que ainda mantêm autonomia física e cognitiva. Sobre a administração desses recursos, elas afirmam:

- É, pra tomar meus remédios e pagando aqui agora no São Vicente. Eu pago (Sra. M., 89 anos, ILPI).

- Mas toda sexta-feira, ela dá trinta conto a gente. Eu faço minhas compras. Agora mesmo vendi uma boneca por cinco conto, boneca de pano, tanto eu faço, como eu vendo (Sra. R., 90 anos, ILPI).

A permanência dos idosos na instituição é determinada não apenas pela ausência de familiares dispostos a oferecer moradia e cuidados, mas pela insegurança de perder o apoio que reconhecem na instituição, também pelas dúvidas em morar com filhos/noras/sobrinhos. Medo de perder a tranquilidade, de voltar para uma situação de violência, de abandono:

- Porque eu gosto, né? Que aqui é bom demais, aqui não falta nada pra gente, só falta saúde. Elas levam pra médico, o médico vem de oito dias aqui, enviam pra um médico de consultório... aqui não falta nada pra gente não (Sra. I, 94 anos, ILPI).

Conformam-se com o novo modelo de vida, em troca da segurança e da garantia de que suas necessidades vitais e sociais são atendidas, embora demonstrem carência de afeto.

\section{4 "Senhoras da caridade"}

As motivações conhecidas para que mulheres adultas e idosas integrem a AIC, Núcleo Campina Grande (PB), e 
realizem ações com gestantes, idosos, crianças carentes e doentes são pautadas no desejo de promover melhorias na vida de indivíduos desfavorecidos socialmente.

Quanto aos critérios de admissão de novos membros na Associação, o Estatuto Social da AIC Brasil, parágrafo $2^{\circ}$, afirma que:

Serão admitidas na AIC-Brasil mulheres católicas e compromissadas com a filantropia, cuja admissão ocorrerá por simples manifestação de vontade das mesmas, podendo as associadas serem excluídas da AIC-Brasil se deixarem de efetuar suas contribuições estipuladas pelo Núcleo ao qual pertencem e/ou se adotarem comportamento incompativel com o exercício e finalidade da atividade filantrópica, bem como atentarem contra a ordem, moral e os bons costumes (POGGIOLI, 2010, p. 160).

Nessa orientação, encontramos aspectos apontados como essenciais: comungar do catolicismo, estabelecer compromisso com a caridade e zelar pela moral e ética na família e na sociedade. Uma voluntária deve seguir tais preceitos para conduzir suas ações no cotidiano da Associação.

Embora os membros da diretoria do Núcleo confirmem os critérios para a admissão, acrescentam que muitas aderem pelo desejo de fazer caridade ao próximo e por terem disponibilidade de tempo. Por ser uma associação feminina, podemos imaginar que mulheres adultas, de diferentes faixas etárias, encontrem espaço no grupo. Todavia, a observação mostrou que o público-alvo são mulheres a partir dos 40 anos. O estado civil, a renda mensal e a formação escolar/acadêmica exercem influência, embora não sejam determinantes. As voluntárias apresentam um perfil socioeconômico semelhante e isso é o que tende a atrair mulheres do mesmo status social.

O "Projeto Alegrar" congrega nove mulheres da AIC, entre 54 e 76 anos e preserva o perfil observado. A maioria 
das voluntárias é de mulheres casadas e apenas uma viúva, professoras universitárias, funcionárias públicas aposentadas e donas de casa.

Indagadas sobre o que condicionou a procura pela Associação, alegam que a consideram uma "associação de credibilidade". Outras afirmam também o desejo de ser uma "senhora de caridade". A AIC é reconhecida como uma entidade administrada por "senhoras" da elite, que ostentam um estilo de vida elevado, e algumas buscam reconhecimento, como "engajadas em causas sociais", com vistas a obter prestígio social. Em momentos de reflexão, enfatizavam que eram escolhidas por Deus para esse trabalho voluntário.

Por outro lado, a "chegada" da aposentadoria atuou como uma mudança na vida, visto que passaram de intensa vida profissional, conciliada com a familiar, para uma condição de inatividade. Após um momento de debate promovido em uma das reuniões da Associação, uma participante confessou frequentar diariamente um supermercado da cidade, porque não conseguia ficar em casa. Era seu "meio de distração", pois se "sentia extremamente solitária". Assim, essa atitude explicita a dificuldade real de pessoas idosas promoverem um novo patamar para o uso do tempo livre de forma criativa e despojar-se de antigas rotinas.

Enquanto a aposentadoria promove, embora com restrições, relativa autonomia para os idosos residentes, para as "senhoras", ela representa a perda da identidade profissional e a necessidade de aceitação da nova condição de "aposentada" (CABRAL, 2002). Algumas relatam o vazio e a necessidade de reinserção social. Para tanto, procuraram o engajamento na AIC. Uma voluntária relata:

- Quando eu me aposentei, fiquei muito deprimida, porque eu fui aposentada por invalidez. Aí eu querendo ser voluntária, porque eu já tinha sido voluntária, num asilo. Ai eu estava procurando um lugar onde eu pudesse ser voluntária (Dona E., 56 anos, AIC). 
Outra enfatiza a procura pela Associação como um refúgio do ócio, da inatividade:

- Eu sou aposentada e estava muito ociosa em casa, sem fazer nada. Então, eu resolvi procurar algo que fizesse que... que realmente me sentisse bem (Dona A., 64 anos, AIC).

A maioria das caridosas afirma que o maior incentivo para se tornar "senhora da caridade" foi o desejo de ajudar os mais necessitados, pobres e a afeição que nutrem pelos idosos, como vemos:

- A vontade que eu sempre tive de cuidar de uma pessoa mais carente, de um idoso que precisa de uma atenção especial. Fui eu que cuidei dos meus pais, eu sempre tive a vontade de levar... de tirar um pouco da solidão desses que aqui se encontram (Dona N., 63 anos, AIC).

- Eu sempre fiquei assim com pena desse povo carente de carinho familiar, uma palavra amiga, tá entendendo? Então, eu quis fazer essa doação. Porque eu me sinto bem com eles. Às vezes, eu penso assim que vou passar uma coisa boa pra eles, mas eu saio daqui fortalecida. Chego em casa fortalecida e com a sensação de missão cumprida (Dona T., 54 anos, AIC).

O desejo de exercer a solidariedade com os idosos é um dos aspectos que assegura a permanência de algumas voluntárias no grupo. E essa solidariedade também atua em prol de si mesmas. Durante a troca de experiências, a condição de vida de um e de outro se coloca frente a frente. Comparações e possiveis conclusões que envolvem a superioridade de uma vivência em relação à outra aparecem sutilmente. Portanto, as atividades da AIC e do "Projeto Alegrar" existem com o objetivo não apenas de distração para os residentes, mas uma "terapia"/"autoajuda" para as voluntárias, sendo um momento para extravasar emoções, renovar energias e se certificarem da satisfatória vida que possuem. 
As voluntárias contam que se adaptaram rapidamente às atividades e dinâmicas cotidianas desenvolvidas na AIC, além de conservarem relações amistosas entre si. A permanência delas no grupo é pautada pela satisfação de executarem atividades que atendam às metas e demandas existentes, além de adquirirem novos vínculos de sociabilidade (CABRAL, 2002), após a aposentadoria e/ou início da velhice.

\section{0 projeto alegrar e a participação dos residentes}

Os encontros promovidos pelas caridosas junto aos residentes se constituem em momentos singulares, reveladores de expressões de "ser velho" e da condição social que vivenciam, bem como explicitam a elaboração da imagem da velhice de si e do outro. Não nos limitaremos na descrição das atividades desenvolvidas pelo Projeto, mas através da observação das relações estabelecidas, analisaremos a perspectiva da alteridade entre idosos inseridos nos dois grupos que pesquisamos.

A Dinâmica dos Encontros. O objetivo do "Projeto Alegrar" é proporcionar momentos de alegria e distração aos residentes semanalmente: o grupo leva músicas, jogos, trabalhos manuais e servem lanches. As voluntárias vestem uniformes, conversam e ouvem relatos, histórias de vida, compartilhando conselhos, experiências, frustrações e conquistas. Comemoram os aniversários e fazem festas com programações específicas, tais como Dia das Mães, São João, Dia dos Pais, Dia do Idoso e Natal.

O "Projeto Alegrar" foi idealizado há cerca de 10 anos por uma pioneira que atuou como coordenadora. Posteriormente, outra assumiu devido à ausência dela. Inicialmente, promovia momentos mais dinâmicos. Organizava passeios em parques, caminhadas e conquistava uma maior adesão em práticas criativas, como pinturas em tecido, jogos, artesanatos em geral. Ultimamente, os idosos demonstram 
perda de interesse nas atividades, em face das limitações ou doenças. Assim, as voluntárias resolveram centralizar as atividades semanais no ambiente da instituição.

Para promover momentos de alegria e entretenimento, as "senhoras" desenvolvem uma prática semelhante. Observamos que ocorre assim: as primeiras voluntárias chegam ao Instituto, às 08h30, na terça-feira, organizam o lanche que, nesse dia, fica sob a responsabilidade delas. Seguem para o refeitório, preparam os pratos de cada indivíduo, com o apoio das funcionárias do local, servindo bolos, biscoitos e refrigerante. Depois, oferecem o lanche aos acamados. Após, arrumam o refeitório e começam a animação com músicas e jogos no salão principal. As nove voluntárias dividem-se para conversar, jogar ou ajudar os idosos nas suas necessidades, de acordo com aptidões e características pessoais. O conteúdo musical alterna cantigas infantis, marchinhas de carnaval e canções religiosas, e os idosos são motivados a cantar e dançar junto com elas. Estimulam também a prática de jogos diversos.

Para esse encontro, as voluntárias vestem uniformes, sinalizando uma distinção delas para as tarefas que realizam. É também uma forma de expressar a identidade do grupo em face da coletividade onde atuam. Na instituição, o horário de visita inicia às 09h30 e finaliza às 10h30. Entretanto, durante as atividades do "Alegrar", o horário é ampliado até às $11 \mathrm{~h}$. Esses dias são percebidos como "especiais" e diferentes da rotina e cheios de expectativas para todos os participantes.

\section{As voluntárias e a participação dos residentes.} Mauss (2003) desenvolve a teoria da reciprocidade a partir de práticas estabelecidas nas sociedades "arcaicas" sobre as quais estudou, destacando a tripla obrigação entre o dar/receber/retribuir entre os individuos. É nesse sentido que as atividades propostas pelas caridosas, acima descritas, apenas têm efeito a partir da aceitação do residente e de sua posterior "retribuição". 
As ações destinadas aos idosos são planejadas pelas "Senhoras" de acordo com as características físicas, subjetivas e socioculturais deles. Assim, sendo lúcidos ou apresentem algumas limitações, são incentivados a jogar bola e conversar. Quanto aos acamados, aguardam a visita delas aos dormitórios. Observamos que muitos participantes não interagem, apesar de receptivos aos diálogos sobre suas histórias e sobre o ambiente da instituição.

Uma voluntária, de 72 anos e há três anos no "Projeto Alegrar", relatou que a maioria não participa das atividades. Para ela, a idade avançada, a saúde debilitada e a personalidade introvertida deles/delas são obstáculos à participação. Apesar disso, muitos demonstram satisfação em face da presença das "Senhoras", reconhecendo cada uma delas e lamentam quando não comparecem. Também constatamos que os próprios idosos se declaram "não ativos", mas gostam de ver e conversar com elas.

Ainda percebemos atitudes de rejeição ao "Alegrar", como expresso por uma idosa:

- Eu não gosto muito não, mas não me importo, porque eu não posso brincar, tenho os braços doentes, aí não gosto não. (...) Pra gente é divertido! Quem gosta e pode, se diverte (Sra. I., 94 anos, ILPI).

Mas também de aceitação, como a Sra. C., 63 anos, portadora de necessidades especiais, em cadeira de rodas, que sempre participa das atividades.

Outras revelam não participar, mas gostar de olhar e conversar. Também constatamos reclamações, devido ao alto volume das músicas, certos afagos ou brincadeiras de mau gosto, reconhecidas como "palhaçadas". Como perguntas: "Quando vai casar? Ou, quer casar?". Chegam a concluir que "velho é tratado como palhaço". Muitas "resmungam" para expressar insatisfação com o tratamento recebido.

Atitudes observadas no que diz respeito à "recepção" dos residentes são expressas, portanto, através de parti- 
cipação ativa, presença mais reservada, bem como indiferença às ações. A "retribuição", por sua vez, é realizada através de sorrisos, abraços, palavras elogiosas, ao que as "Senhoras" afirmam se sentirem realizadas com as expressões de agradecimentos.

Podemos considerar que a caridade realizada nem sempre está em conformidade com a concepção de "amor ao próximo". Conflitos também aparecem entre as participantes do grupo de voluntárias. Observamos que comentavam sobre as ausências e que era perceptivel que algumas expressavam amor pelas tarefas, enquanto outras só frequentavam a ILPI para "bater papo", principalmente as "velhinhas" do grupo, referindo-se às mais idosas do Projeto em questão. Quanto às relações com os residentes, algumas "Senhoras" demonstravam momentos de incompreensão, em face das limitações deles. Demonstravam impaciência para ajudar a deslocar idosos no espaço, assim como o fato de estimular uma recém-admitida, que se vestia de forma exagerada, a cantar para todos rirem dela.

Observamos que as práticas da caridade são nuançadas dentro e fora do grupo. Ao mesmo tempo em que assumem a responsabilidade de promover uma ruptura na rotina dos residentes, com momentos de alegria e entretenimento, algumas voluntárias não compreendem de forma ampla a condição peculiar de cada idoso que ali reside e reproduzem práticas de exclusão e de invasão na privacidade/individualidade dos residentes.

\section{As senhoras e os residentes: imagem de si so- bre si e em relação ao outro}

Imagens de si, imagens do outro. Nos estudos antropológicos, a perspectiva da alteridade é discutida recorrentemente. Povos primitivos versus civilizados, indigenas versus brancos, jovens versus velhos, as diferenças territoriais, 
étnicas, geracionais, sociais são postas em extremos. Aqui, pretendemos debater a noção e a prática da alteridade e como esta acontece através do encontro entre sujeitos que compartilham o mesmo estágio no curso da vida, com relação à velhice, entre idosas de grupos distintos num ambiente institucional, mas que possuem distintas trajetórias de vida e inserções sociais. Empreendemos uma análise por dentro da velhice, verificando os aspectos que demarcaram as diferenças presentes no processo de envelhecer.

Em obra clássica, "A Velhice”, Beauvoir (1990) afirmou que os idosos antes resistem à velhice, que a ela procuram se adaptar. "Velho é sempre o outro, pois a velhice é uma realidade incômoda". É neste sentido que discutimos, uma vez que não se trata apenas de perceber e analisar a si próprio e ao outro enquanto idosos, mas de elaborar a sua imagem a partir do encontro e relação estabelecida com esse outro.

Buscamos conhecer como os idosos constroem suas representações do que é "ser velho" e quais critérios acionam para elencar elementos que demarcam a velhice. Esse exercício busca, através dos relatos dos próprios sujeitos, perceber o que caracteriza o outro, como se reconhecem como parte daquela realidade e encontram semelhanças, comparando à sua experiência particular de velhice. $\mathrm{O}$ confronto, realizado na forma de encontro, entre diferentes formas de vivenciar a velhice é pontuado por observações e relatos sobre as diferenças no processo de envelhecer presentes neste estudo.

\section{Entre práticas e significados: percepções sobre "ser velho/a" para as "senhoras da caridade" e os idosos residentes}

Reconhecer a velhice como inerente à condição biológica da humanidade encontra resistência desde sempre. A reflexão sobre como "será a velhice" é uma questão real 
e constitui-se em uma prática que os indivíduos resistem, mas terminam por realizar. Entretanto, enfrentar a presença da velhice na vida é um desafio e provoca diferentes avaliações do que julgavam "próprio" do envelhecer ao experimentar "ser velho".

Como apontado por Debert:

Na pesquisa antropológica, muitas vezes é a impressão que o pesquisador tem sobre a aparência do pesquisado que o leva a caracterizar os indivíduos como velhos. Outras vezes, é a autodefinição do informante e, na maioria das vezes, uma determinação aproximada de sua idade cronológica $(2007$, p. 55).

Nossa discussão está, portanto, buscando não apenas autodefinição do informante, mas a articulação entre fontes teóricas e impressões advindas do campo. Assim, o período de pesquisa na AIC e no "Alegrar" revelou certo temor entre as mulheres em serem identificadas como idosas. Em todo momento, defendem-se e se autodefinem: "Não somos velhas, somos experientes" ou "Velhas não, idosas". Demonstram rejeitar inclusive expressões de tratamento, tais como "senhora" e "dona", porque implica nomeá-las "velhas".

Numa reunião das "Senhoras", para refletir o tema "Terceira Idade", como parte da programação do Dia Nacional do Idoso, o debate pós-palestra envolveu as noções de nomenclatura utilizadas para se referir aos individuos "de mais idade". Quando recaíram nos termos "idosos versus velhos" e a chamada "terceira idade ou "melhor idade", iniciou-se um debate acalorado entre duas "Senhoras", quando defendiam percepções divergentes a respeito da questão. Uma declarava:

- Quem diz que a 'terceira idade' é a 'melhor idade' é hipócrita. Eu mesma vivo cheia de doenças que não tinha. Que melhor idade que nada!. 
A outra debatedora respondia:

- Não é hipocrisia, porque quem faz a idade é a pessoa.

Considera-se idosa, mas deixa claro que não é velha, porque ainda não parou.

- Estou ficando velha, ainda não sou.

Mas refere-se aos residentes como "velhinhos". Interessante perceber que ela é vaidosa, as peças de vestuário e os cosméticos de beleza utilizados expressam essa vivacidade afirmada pela mesma. Outra, de 72 anos, afirma pensar na sua própria velhice, mas como futuro e não presente:

- Já tô me preparando, tô no caminho. Me relaciono bem com isso (Dona O., 72 anos, AIC).

Embora "oficialmente" inseridas numa idade que é demarcada como "idosa", não se reconhecem assim. Segundo as caridosas, os principais aspectos que indicam a chegada da velhice são os seguintes:

- A maior característica é o esquecimento. A saúde também, porque geralmente os idosos são mais propensos a ficar doentes que os jovens (Dona O., 72 anos, AIC).

- Primeiro aspecto de ser idoso, mais velho, menos velho, é o estado de saúde do velhinho. Se o velho pode ter oitenta anos e ter um estado de saúde bom, não tem nada (Dona G., 76 anos, AIC).

- ... Idade pra mim não é ser idoso não, de jeito nenhum. É como ele fica, é o estado físico que determina o idoso, não é a idade. O que determina o idoso é apenas a saúde dele (Dona E., 56 anos, AIC).

- Olha, quando a pessoa passou dos sessenta, já começa a sentir velho e os que têm a felicidade de ter a família boa, carinhosa, é bom (Dona A., 64 anos, AIC). 
Nota-se uma tendência em associar a velhice à presença de doenças e limitações. Interessante que na medida em que definem os elementos demarcadores, afastamse do perfil que esboçam e estabelecem diferenças ou até uma total dissociação entre a própria experiência de envelhecer e a dos residentes idosos. Estes, por sua vez, não demonstram receio em se identificarem com a expressão "velhos/as", é parte da rotina deles comentarem:

- Tu viu a velha como chegou nervosa?

- Já conheceu a velha que chegou?

- Essa velha não tem mais juizo,

quando se referiam aos recém-chegados e àqueles que se locomoviam, mas já apresentavam limitações cognitivas.

Assim, os residentes explicitam dificuldade em definir os elementos que identificam a velhice. Ainda demonstram estar falando de si próprios, de uma experiência que lhes diz respeito. Vejamos:

- Velho é ter paciência, é esperar a vontade de Deus. Velho é assim, doente, não quer saber mais de nada, não é? (Sra $R ., 90$ anos, ILPI).

- É mais esse... esse viver afastado, é estar afastado da comunicação, né? Uma vida parada sei lá como (Sra. M., 89 anos, ILPI).

Entre as voluntárias, reconhece-se a resistência ao tratamento como "idosa" e, ainda mais, "velha". No caso dos residentes, o perfil é distinto, visto que há aceitação e reconhecimento da própria experiência, porém, salientase "não quero ser, mas sou", que diferencia-se do "estou ficando, mas não sou", das caridosas.

As representações da velhice, através dos relatos de sujeitos que vivenciam a condição de ser velho, explicitaram associações que comumente são encontradas na abordagem sobre o envelhecer: doenças, decrepitude, esquecimentos. 
Acrescido a isso, verificou-se uma constante tentativa de distanciamento da possibilidade de fazer parte do "grupo" tão negativamente definido por eles próprios, bem como uma aceitação por parte dos residentes, ainda que não houvesse o desejo de estar vivenciando a velhice.

\section{0 confronto entre o eu e outro na velhice}

O primeiro confronto proposto pela presente pesquisa foi: a realidade institucional versus a realidade aberta. A experiência de ser velho e residir numa ILPI, instituição total (GOFFMAN, 2008), é significativamente distinta da possibilidade de ser velho, ter uma vida social e apenas visitar a instituição, colaborando em atividades para seus residentes. Esse confronto não aconteceria apenas em extremos de condições de vida distintas na velhice, mas em termos relacionais, através da perspectiva da alteridade. Como analisado por Jovchelovict:

O outro não está simplesmente lá, esperando para ser conhecido pelo sujeito do saber. Ao contrário, o outro está lá, ele próprio, enquanto eu, com projetos que lhe são próprios, desejos que lhe são próprios, perspectivas que lhe são próprias. Ele não é redutivel do que o eu pensa ou sabe sobre ele, mas é precisamente o "outro", irredutivel na sua alteridade. Existem muitas formas de envolvimento com o outro e essa diversidade de formas conduz não só a diferentes concepções do próprio eu, mas também a diferentes relações entre o eu e o outro (1998, p. 74, grifo do autor).

O confronto entre vivências particulares e entre um "futuro temido" pelas voluntárias de caridade é realizado no próprio interior do grupo. Observamos também um conflito entre as voluntárias, com idade inferior a 75 anos e a outra acima de 75 anos. Muitas vezes, os conflitos 
geracionais eram explicitados em situações-limite, nas quais surgiam opiniões divergentes e incompreensões.

A representação da velhice está fortemente associada a estigmas socialmente ligados à decadência física, e a percepção que as pessoas envelhecidas têm da sua própria imagem muda à medida que o tempo passa; o confronto com a velhice provocado, principalmente, pela inatividade ocasionada pela aposentadoria, cria múltiplas facetas na representação da decadência e do envelhecer (PEIXOTO, 1997, p. 156).

A imagem que possuíam a respeito da velhice e dos idosos, carregada de estereótipos, contrasta com sua própria experiência de velhice, suas limitações, bem como as possibilidades de atuação que ainda vislumbram no campo individual e coletivo, junto à família e ao grupo de caridade.

- (...) Tem pessoas que quando começam a envelhecer, se trancam, não se comunicam, não procuram atividades. E as pessoas que demoram a envelhecer, se comunicam, têm atividades. É o que procuro fazer (Dona O., 72 anos, AIC).

- Hoje, eu tô ficando idosa, claro, né? Bem feliz e satisfeita. Eu tenho idoso como uma pessoa qualquer, um mais velho, que realmente fica mais velho, uma pessoa de 90 anos pra frente, eu acho que já fica mais velho, mesmo que seja lúcido (Dona G., 76 anos, AIC).

Para as caridosas, a percepção de velhice de si mesmas diante do quadro da ILPI revela expressões de não reconhecimento e/ou a tentativa de definir a distância que caracteriza sua vida e a do outro, residente.

- Eles são muito carentes de carinho, a vivência deles é uma vivência de tristeza, porque eles não têm apoio familiar. Falta o principal: a família. A presença da família (...) Eu não comparo com a minha vida, de jeito nenhum, porque ainda eu tô nova em relação a eles. Comparação com eles, a gente não 
pode comparar porque a gente tem vida boa ainda, ainda tá com saúde, na faixa etária que pode fazer alguma coisa $e$ eles não (Dona E., 56 anos, ILPI).

- Eu vejo uma diferença grande entre a minha vida e a dos idosos, porque eu posso dar carinho, amor e eles não têm essa parte, sabe? (Dona A., 64 anos, ILPI).

- Quando eu vejo os velhos aqui, percebo que é muito bom quando a gente faz as coisas pra gente, mas quando a gente fica aquele velho que é você quem cuida, você quem bota a comida na boca, é uma vida que sinceramente, eu só aceito diante de Deus, que tenho que aceitar. Eu tenho muita pena daqueles velhinhos quase ou totalmente dependentes (Dona G., 76 anos, ILPI).

Como discutido por Barros em uma pesquisa realizada com um grupo de mulheres idosas:

[...] o que as mulheres da pesquisa viviam como velhice era um momento dúbio, pois ao mesmo tempo em que era percebido como presente, era adiado para um tempo futuro. A visão da debilidade fisica e mental de pessoas da mesma idade, o internamento de conhecidos ou parentes em asilos para velhos, a morte de alguém próximo traziam a presença da velhice. Mesmo que essa presença viesse como uma comparação, afastada delas mesmas, essa comparação mostrava que a ameaça existia e que elas deviam estar o tempo todo atentas para pressenti-la (2007, p. 145).

Entre as caridosas que se aproximam dos 60 anos, há o consenso de que o contato com residentes possibilita reflexões a respeito de sua experiência vindoura. Diante do reconhecimento de inúmeros desafios com os quais o idoso brasileiro se depara, as voluntárias percebem a necessidade de educar as gerações mais jovens para saber lidar com os idosos e o envelhecimento de uma forma geral (CABRAL; MELO; SILVA, 2011). 
Embora os residentes não reconheçam as voluntárias como imagem de sua própria velhice, seus relatos assemelham-se à percepção de não identificação de "ser velho" pelas caridosas, mas com outros significados:

- As mulheres são novas, olha só pra elas, dançando! São novas, né? (Sra. R., 90 anos).

Observações realizadas revelaram não identificação entre as experiências de velhices sobre as quais nos debruçamos. Embora houvesse certo reconhecimento da sua própria velhice, diante dos residentes, as idosas participantes do grupo de caridade explicitavam a superioridade de suas vivências, sendo notória a distinção entre sua velhice em relação à dos residentes. Estes igualmente não expressavam reconhecer entre as idosas do "Alegrar" uma imagem da velhice e, menos ainda, da sua própria experiência.

\section{À guisa de conclusão}

As distinções de gênero, geração, classe social, grupos e contextos especificos contribuem para elaborar a representação da identidade individual e coletiva de ser velho/a. A possibilidade de vivenciar a velhice de forma autônoma e desfrutar de privilégios econômicos e sociais, por exemplo, são elementos de distinção que contrapõem-se a uma realidade de dependência, em ambiente da ILPI. O exercício de confrontar duas realidades, praticando o princípio da alteridade, possibilitou que os sujeitos sociais refletissem sobre sua condição de vida atual a partir de si mesmos e de um outro, também idoso, mas distinto em sua trajetória de vida. Essa reflexão constituiu-se em uma análise sobre subjetividades, identidades e características socioculturais, explicitou diferenças presentes no processo de envelhecer buscando contribuir para ampliar a representação da "velhice". 


\section{Referências}

BARROS, M. M. L. Testemunho de vida: um estudo antropológico de mulheres na velhice. In: BARROS, M. M. L. (Org.). Velhice ou terceira idade? Estudos antropológicos sobre identidade, memória e política. - reimpr. - Rio de Janeiro: Editora FGV, 2007.

BEAUVOIR, S. A Velhice. Rio de Janeiro, Nova Fronteira, 1990.

BORN, T; BOECHAT, N. S. A qualidade dos cuidados ao idoso institucionalizado. In: FREITAS, E. et al (Org.). Tratado de Geriatria e Gerontologia. Rio de janeiro: Guanabara; Koogan, 2002.

CABRAL, B. E. S. L. Recriar Laços: estudo sobre idosos e grupos de convivência nas classes populares paraibanas. Tese (doutorado)- UNICAMP/Campinas, 2002.

MELO, J. A. B; SILVA, K. R. Universidade e questões geracionais educar para o envelhecimento na sociedade e na familia. In: D'ALENCAR, R. S., OLIVEIRA, R. C. S. As experiências de universidades abertas em um Brasil que envelhece. Curitiba, PR: CRV, 2011.

DEBERT, G. G. A Reinvenção da Velhice: Socialização e Processos de Reprivatização do Envelhecimento. São Paulo: Editora da Universidade de São Paulo: Fapesp, 1999.

A antropologia e o estudo dos grupos e das categorias de idade. In: BARROS, M. M. L. (Org.). Velhice ou terceira idade? Estudos antropológicos sobre identidade, memória e política - reimpr - Rio de Janeiro: Editora FGV, 2007.

GOFFMAN, E. Manicômios, prisões e conventos. São Paulo: Editora Perspectiva, 2008.

JOVCHELOVICT, S. Re(des)cobrindo o outro. In: ARRUDA, A. (Org.) Representando a alteridade. Petrópolis, RJ: Vozes, 1998.

[86] A REPRESENTAÇÃO SOCIAL NA CONSTRUÇÃO DA VELHICE 
MAUSS, M. Ensaio sobre a Dádiva. Forma e Razão da Troca nas Sociedades Arcaicas. Sociologia e Antropologia. Ed. Cosay \& Naify: São Paulo, 2003.

PEIXOTO, C. Histórias de mais de 60 anos. In: MOTTA, A. B. (Org.). Dossiê Gênero e Velhice. In: Revista de Estudos Feministas, v. 5. n. 1/97. Instituto de Filosofia e Ciências Sociais - UFRJ: Rio de Janeiro, p. 159-168, 1997.

POGGIOLI, M. D. (Org.). Fundamentos Básicos da AIC-Brasil. São Paulo: Catálise, 2010. 